\title{
Effects of the Motivation for Rehabilitation on the Functional Performance of Stroke Patients
}

\author{
So Ra Kil, Sung Min Son \\ Department of Physical Therapy, Graduate School of Health Science, Cheongju University, Cheongju, Korea
}

Purpose: This study examined whether the motivation for rehabilitation influences the functional performance of stroke patients.

Methods: To elucidate the same, correlation analysis between the 'rehabilitation motivation level' and 'functional performance improvement' was performed. Thirty-three stroke patients, who were hospitalized in rehabilitation and nursing hospitals, were enrolled in this study. Functional performance was assessed using the 10MWT, FRT, and the BBS. Statistical analysis was performed to determine the correlation between the reactivation symptoms and rehabilitation therapy at four weeks, eight weeks, and 12 weeks.

Results: The results showed a significant correlation between the reactivation symptoms and rehabilitation therapy, as evidenced by the 10MWT, FRT, and BBS (8-12 weeks 10M gait test, Berg balance scale for 4-8 weeks, and 8-12 weeks). The FRT did not reveal any significant correlation between the rehabilitation program and reactivation.

Conclusion: The present study confirmed that a higher motivation for rehabilitation in stroke patients resulting in a higher likelihood of it acting as a factor in improving their functional ability. Based on the above-mentioned results, this study suggests that a rehabilitation program could be considered for the motivation of patients to participate in a rehabilitation program.

Keywords: Rehabilitation motivation, Functional performance, correlation

\section{서 론}

뇌졸중은 전 세계적으로 중요한 사망 원인 중 하나로 알려져 있다. 한 국의 경우 뇌졸중으로 인한 사망은 2015년 인구 10 만 명당 49.7명으 로 2005년에 64.1명이었던 것에 비해 25.1\%가 감소하였으나 암, 심장질 환에 이어 여전히 사망원인 3 위를 차지하고 있다.' $\mathrm{WHO}$ 는 전 세계적 으로 6 명 중 1 명이 생애 주기 중 뇌졸중을 경험할 것이라고 하였고, 일 반적으로 뇌졸중 환자중의 $10 \%$ 만이 완전히 회복되며, $15-20 \%$ 는 약간 의 장애를 겪게 되고 나머지 70-75\%는 완전히 회복되지 못하고 손상 된 뇌의 부위에 따라 편 마비를 비롯하여 운동장애, 감각장애, 보행 장애, 일상생활동작, 통증, 정서장애 등의 문제를 동반하게 된다.

이런 다양한 신경학적 기능장애를 가진 뇌졸중 환자는 초기부터 빠른 일상복귀를 위한 앉기, 걷기 등의 체계적인 재활이 중요하다. 뇌 졸중 환자의 재활은 신체적 기능장애의 회복뿐만 아니라 심리적, 사 회적 스트레스에 적절히 대처하도록 두 가지의 요인을 만족시킬 수 있는 포괄적 중재가 요구되는 과정이라고 볼 수 있으며, ${ }^{3}$ 재활의 모든

Received Dec 31, 2019 Revised Feb 3, 2020

Accepted Feb 20, 2020

Corresponding author Sung Min Son

E-mailssm0417@hanmail.net
단계에 있어 의료인의 역할 뿐만 아니라 환자 스스로의 참여가 재활 의 성과에 영향을 미칠 수 있으므로 성공적인 재활을 위해서는 변화 의 핵심요소인 동기와 능력에 관심을 가져야 할 필요가 있다. ${ }^{4}$

많은 재활전문가들은 환자의 재활동기가 뇌졸중 대상자의 기능적 변화 결과에 가장 중요한 역할임을 강조하였으며, ${ }^{5}$ 이와 같이 재활동 기는 환자의 행동, 재활의 방향성과 강도, 지속성에 영향을 주고 재활 과정을 성공으로 이끄는 중요한 변수로 작용할 수 있고, ${ }^{6}$ 치료사는 뇌졸중 환자의 재활동기를 파악하고 적극적인 재활의지를 북돋아 주어야한다.

지금까지 뇌졸중 환자의 재활동기와 관련된 선행연구들을 살펴보 면 $\mathrm{Kim}^{7}$ 은 재활 수행능력과 재활동기와의 상관관계가 부양자의 부 양부담이 적을수록 재활동기가 높다는 결과를 설명하였으며, 뇌졸 중 환자의 재활동기가 가족지지 및 자기 효능감에 미치는 영향에서 는 재활동기와 가족지지, 재활이행, 자기 효능감이 유의한 정적 상관 관계가 있다고 하였다. 이외에도 뇌졸중 환자의 재활동기에 미치는 다양한 역학적 요인에 대한 연구, 뇌졸중 환자의 우울, 재활동기, 일
Copylight (C)2020 The Korean Society of Physical Therapy

This is an Open Access article distribute under the terms of the Creative Commons Attribution Non-commercial License (https:// creativecommons.org/license/by-nc/4.0.) which permits unrestricted non-commercial use, distribution, and reproduction in any medium, provided the original work is properly cited. 
상생활동작이 삶의 질에 미치는 영향, ${ }^{10}$ 뇌졸중 환자의 우울, 가족지 지, 의료인 지지가 재활동기에 미치는 영향11 등에서 재활동기와 영향 을 미치는 여러 가지 요인들을 확인하였다. 하지만, 선행연구들에서 는 재활동기에 영향을 미치는 요인들에 대한 연구나 재활동기에 따 라 버그균형척도(Berg balance scale, BBS), 10미터 보행검사, 기능적 팔 뻗기 검사(functional reaching test, FRT)와 같은 기능적 수행능력의 변 화에 직접적으로 영향을 미치는지 확인한 연구는 미비한 실정이다. 따라서 본 연구의 목적은 뇌졸중 환자의 재활동기 수준과 기능적 수 행능력 향상 정도와의 상관분석을 통해 재활동기가 기능적 수행능 력 향상에 영향을 미치는지 확인하는 것이다.

\section{연구 방법}

\section{1. 연구 대상자}

본 연구는 뇌졸중 환자 35 명을 대상으로 진행하였으며, 12 주 연구기 간 동안 중도 탈락한 2 명을 제외한 33 명을 대상자로 최종 진행하였다. 대상자 선정조건은 다음과 같다. 1) 뇌졸중 진단을 받고 6 개월 이상 혹은 2년 미만이 경과한 자, 2) 보조기나 보조도구를 사용하여 $10 \mathrm{~m}$ 이상 독립보행이 가능한자, 3) 심호흡계 문제가 없고 상지 및 하지의 정형외과적 질환이 없는 자, 4) 한국어판 간이 정신상태 검사(minimental state examination Korean version)에서 24점 이상을 받은 인지 장애가 없는 자로 하였다. 실험 전 연구대상자들에게 연구 목적과 절 차에 대해 충분한 설명을 하였으며, 모든 대상자들은 실험에 참여하 는 것을 서면 동의하였다.

\section{2. 평가도구 및 측정방법}

\section{1) 재활참여동기}

본 연구에서는 뇌졸중 환자의 재활동기 수준을 측정하기 위하여 $\mathrm{Han}^{12}$ 이 개발하고 $\mathrm{Kim}^{10}$ 이 뇌졸중 환자에 맞게 수정한 재활참여동 기 측정도구를 사용하였다. 본 도구는 27 개 문항, 4 점 척도로 구성되 어 있고 자기-결정 정도에 따라 5 개의 동기유형이 포함된 다차원적 도 구이다. 과제지향적 동기(8문항), 변화지향적 동기(7문항), 의무적 동 기(4문항), 외부적 동기(4문항), 무동기(4문항)로 구성되었고, 점수가 높을수록 재활동기가 높다는 것을 의미한다. 본 도구의 측정자 내 신 뢰도는 $r=0.86$, 측정자 간 신뢰도는 $r=0.82$ 로 보고되었다. ${ }^{10}$

2) 10 미터 보행검사(10 m walk test, 10MWT)

$10 \mathrm{MWT}$ 는 $14 \mathrm{~m}$ 의 직선경로에서 측정하였으며, 처음 가속구간 $2 \mathrm{~m}$ 와 감속구간 $2 \mathrm{~m}$ 를 제외한 $10 \mathrm{~m}$ 의 중간구간을 걷는데 걸리는 시간을 스 톱워치를 사용하여 측정하였다. $10 \mathrm{MWT}$ 는 측정자 내 신뢰도는 $\mathrm{r}=.88$ 이고, 측정자 간 신뢰도는 $\mathrm{r}=.99$ 로 보고되었다. ${ }^{13}$

\section{3) 버그균형척도(BBS)}

버그균형척도, 즉 BBS는 1989년 Berg 등에 의해 노인들의 낙상 위험도 를 평가하기 위한 목적으로 개발되었다. 서기, 앉기, 자세 변화의 3 개 의 영역에 속하는 14 개 항목을 평가하는 도구로 각 항목은 5 점 척도 (0-4점)로 구성되어 총 56점으로 계산되어 총 56점 만점으로 계산하 였으며, 점수가 높을수록 균형 능력이 좋은 것으로 평가하여, 0 점은 수행이 불가능한 경우이며, 4 점은 독립수행이 가능한 경우로 표기하 였다. 본 측정도구는 측정자 내 신뢰도와 측정자 간 신뢰도가 각각 $\mathrm{r}=.99$ 와 $\mathrm{r}=.98$ 로써 높은 신뢰도를 보인다. ${ }^{14}$

\section{4) 기능적 팔 뻗기 검사(FRT)}

정적 균형능력을 알아보기 위해 시행하였으며 줄자를 대상자의 견봉 높이에 지면과 평행하게 하여 벽에 붙이고, 대상자의 건측 어깨가 벽 을 향하도록 하여 일직선 위치에서 양발을 어깨너비로 벌리고 편히 서게 한 다음 주먹을 쥔 상태에서 건측 팔꿈치 관절을 펴고 어깨관절 을 $90^{\circ}$ 로 올려 견봉과 줄자의 $0 \mathrm{~cm}$ 지점이 일치하도록 하였다. 어깨가 벽에 닿거나 전방으로 몸을 기울이는 동안 팔이 벽에 닿지 않도록 어 깨와 벽과는 $5 \mathrm{~cm}$ 간격을 두었으며. 대상자가 팔을 뻗어 세 번째 손가 락뼈 원위부가 위치한 처음 거리에서 최대한 몸을 전방으로 이동시 켜서 5 초간 유지할 수 있는 상태까지의 이동 거리를 $\mathrm{cm}$ 단위로 측정 하였으며, 3 회 반복하여 평균값을 구하였다. 본 평가의 신뢰도와 측 정자간 신뢰도는 각각 $\mathrm{r}=.89, \mathrm{r}=.98$ 로 보고되었다. ${ }^{15}$

\section{3. 연구절차}

본 연구에 참여한 대상자들은 재활병원에서 1 일당 중추신경계발달 치료 2 회, 보행치료 2 회, 기능적 전기자극치료 2 회, 30 분씩 주 5 회 12 주 동안 동일한 치료를 받았으며 연구시작 시점에서 대상자의 재활 동기를 평가 후 각각 4 주, 8 주, 12 주차에 기능적 수행능력향상척도로 사용한 BBS, $10 \mathrm{MWT}$, FRT를 측정하였다. BBS 4주차 측정치에서 BBS 8 주차 측정치의 차이를 $\mathrm{BBS}$ 기능적 변화량 $1, \mathrm{BBS} 8$ 주차 측정치에서 $\mathrm{BBS} 12$ 주차 측정치의 차이를 BBS 기능적 변화량 2 로 정의하였고 $10 \mathrm{MWT}$ 와 FRT도 동일한 방법으로 작성하여 10MWT 4주차 측정치 와 8 주차 측정치의 차이를 $10 \mathrm{MWT}$ 기능적 변화량 $1,10 \mathrm{MWT} 8$ 주차 측정치와 12 주차 측정치의 차이를 $10 \mathrm{MWT}$ 기능적 변화량 2 로 정의 하였고 FRT 4주차 측정치에서 FRT 8주차 측정치의 차이를 FRT 기능 적 변화량 $1, \mathrm{FRT} 8$ 주차 측정치에서 12 주차 측정치의 차이를 FRT 기 능적 변화량 2 로 정의하였다.

\section{4. 통계처리방법}

수집된 자료는 SPSS 22.0 (IBM Co., Armonk, NY, USA) 프로그램을 이 용하여 통계 분석하였고, 통계학적 유의수준 $\alpha<0.05$ 로 정하였다. 대 
상자의 일반적인 특성은 빈도와 백분율을 사용하였고, 대상자의 나 이, 유병기간, 재활동기 및 기능적 수행능력은 기술통계 분석을 통하 여 평균과 표준편차로 나타내었다. 그리고 대상자의 재활동기와 기 능적 수행능력의 향상 정도에 대해서 상관관계를 확인하기 위하여 피어슨 상관 계수(pearson correlation coefficient)를 사용하였다.

\section{결 과}

\section{1. 연구대상자의 일반적 특성}

성별은 남성 $60.6 \%$ (20명), 여성 39.3\% (13명)로 구성되었다. 대상자들 의 나이차는 $65.57 \pm 12.32$, 유병기간은 $15.87 \pm 5.4$ 로 나타났다. 대상자 들의 유병기간별 분포는 6개월 이상 12 개월 미만이 $24.2 \%$ ( 8 명), 13 개 월 이상 18 개월 미만이 $36.3 \%$ (12명)으로 구성되었으며 19 개월 이상 24 개월 미만이 $39.3 \%$ (13명)을 차지하였다.

\section{2. 연구대상자의 기능적 수행능력}

연구대상자들의 4 주, 8 주, 12 주차 기능적 수행능력에 대한 평균과 표 준편차는 Table 1 와 같다. 대상자들의 BBS 측정점수는 4 주차 $32.45 \pm$ $11.07,8$ 주차 $\mathrm{BBS}$ 측정점수 $35.81 \pm 10.06,12$ 주차 $\mathrm{BBS}$ 측정점수는 38.27

Table 1. Functional performance of the subjects

\begin{tabular}{lccl}
\hline & \multicolumn{1}{c}{4 week } & \multicolumn{1}{c}{8 week } & \multicolumn{1}{c}{12 week } \\
\hline BBS & $32.45 \pm 11.07$ & $35.81 \pm 10.06$ & $38.27 \pm 9.96$ \\
1OMWT & $39.32 \pm 29.91$ & $34.08 \pm 26.71$ & $31.96 \pm 26.28$ \\
FRT & $8.42 \pm 7.56$ & $10.07 \pm 6.58$ & $11.58 \pm 7.04$ \\
\hline
\end{tabular}

Mean $\pm S D$, mean \pm standard deviation.

BBS: berg balance test, 10MWT: $10 \mathrm{M}$ walking test, FRT: functional reaching test.
土9.96로 나타났다. $10 \mathrm{MWT}$ 에서는 4주차 $39.32 \pm 29.91,8$ 주차 $34.08 \pm$ $26.71,12$ 주차 $31.96 \pm 26.28$ 로 나타났다. FRT는 4주차 $8.42 \pm 7.56,8$ 주차 $10.07 \pm 6.58,12$ 주차 $11.58 \pm 7.04$ 로 측정되었다.

\section{3. 연구대상자의 기능적 수행능력 향상의 변화량}

연구대상자들의 기능적 수행능력 향상의 변화량에 대한 평균과 표 준편차는 Table 2 와 같다. 대상자들의 BBS 기능적 변화량 1 은 $3.36 \pm$ $2.93, \mathrm{BBS}$ 기능적 변화량 2 는 $2.45 \pm 2.94$ 로 나타났으며, $10 \mathrm{M}$ 기능적 변 화량 1 은 $-5.23 \pm 6.96$ 으로 나타났다. $10 \mathrm{M}$ 기능적 변화량 2 는 $-2.12 \pm$ 5.42 , FRT 기능적 변화량 1 은 $1.65 \pm 3.58$ 로 나타났으며, FRT 기능적 변 화량 2 는 $1.50 \pm 3.81$ 로 나타났다.

\section{4. 연구대상자의 재활동기와 각 변수 간의 상관관계}

연구대상자들의 재활동기와 기능적 수행 능력 향상 정도와의 상관 관계 분석 결과는 Table 3 과 같다. 재활동기와 BBS 기능적 변화량 1 사

Table 2. Change in functional performance improvement of the subjects

\begin{tabular}{lc}
\hline & Mean \pm SD \\
\hline BBS1 & $3.36 \pm 2.93$ \\
BBS2 & $2.45 \pm 2.94$ \\
$10 M 1$ & $-5.23 \pm 6.96$ \\
$10 M 2$ & $-2.12 \pm 5.42$ \\
FRT1 & $1.65 \pm 3.58$ \\
FRT2 & $1.50 \pm 3.81$ \\
\hline
\end{tabular}

BBS1, BBS 4 to 8 weeks functional variation; BBS2, bbs 8 to 12 weeks functional variation; $10 \mathrm{M} 1,10 \mathrm{MWT} 4$ to 8 weeks functional variation; $10 \mathrm{M} 2,10 \mathrm{MWT} 8$ to 12 weeks functional variation; FRT1, FRT 4 to 8 weeks functional variation; FRT2, 8 to 12 weeks functional variation.

Table 3. Correlation between the Reactors and the Variables of the Subjects

\begin{tabular}{|c|c|c|c|c|c|c|c|c|}
\hline & & & BBS1 & BBS2 & $10 \mathrm{M} 1$ & $10 \mathrm{M} 2$ & FRT1 & FRT2 \\
\hline \multirow[t]{2}{*}{ Motivation } & $r$ & 1 & & & & & & \\
\hline & $\mathrm{p}$ & & & & & & & \\
\hline \multirow[t]{2}{*}{ BBS1 } & $r$ & $0.638^{*}$ & 1 & & & & & \\
\hline & $\mathrm{p}$ & 0.000 & & & & & & \\
\hline \multirow[t]{2}{*}{ BBS2 } & $r$ & $0.389^{*}$ & $0.627^{*}$ & 1 & & & & \\
\hline & $p$ & 0.025 & 0.000 & & & & & \\
\hline \multirow[t]{2}{*}{$10 \mathrm{M} 1$} & $r$ & $-0.536^{\star}$ & $-0.595^{*}$ & $-0.703^{*}$ & 1 & & & \\
\hline & $\mathrm{p}$ & 0.001 & 0.000 & 0.000 & & & & \\
\hline \multirow[t]{2}{*}{$10 \mathrm{M} 2$} & $r$ & -0.304 & $-0.530^{*}$ & $-0.583^{*}$ & $0.637^{*}$ & 1 & & \\
\hline & $\mathrm{p}$ & 0.085 & 0.002 & 0.000 & 0.000 & & & \\
\hline \multirow[t]{2}{*}{ FRT1 } & $r$ & $0.421^{*}$ & $0.710^{*}$ & 0.295 & -0.310 & -0.223 & 1 & \\
\hline & $\mathrm{p}$ & 0.015 & 0.000 & 0.096 & 0.079 & 0.213 & & \\
\hline \multirow[t]{2}{*}{ FRT2 } & $r$ & 0.105 & -0.051 & 0.271 & -0.157 & -0.284 & $-0.521^{*}$ & 1 \\
\hline & $\mathrm{p}$ & 0.562 & 0.778 & 0.127 & 0.383 & 0.110 & 0.002 & \\
\hline
\end{tabular}

${ }^{*} \mathrm{p}<0.05$.

BBS1, bbs4 to 8 weeks functional variation; BBS2, bbs 8 to 12 weeks functional variation; $10 \mathrm{M} 1,10 \mathrm{MWT} 4$ to 8 weeks functional variation; $10 \mathrm{M} 2$, $10 \mathrm{MWT} 8$ to 12 weeks functional variation; FRT1, FRT4 to 8 weeks functional variation; FRT2, 8 to 12 weeks functional variation. 
이에서는 높은 상관관계를 가지고 있었고 $(r=0.638, p<0.00), \mathrm{BBS}$ 기능 적 변화량 2 사이에서는 중간 상관관계를 나타내었다 $(\mathrm{r}=0.389$, $\mathrm{p}<0.05)$. 재활동기와 $10 \mathrm{MWT}$ 기능적 변화량 1 사이에서는 중간 상관 관계를 가지고 있었고 $(r=-0.536, p<0.00)$, FRT 기능적 변화량 1 사이 에서는 중간 상관관계를 보였다 $(\mathrm{r}=0.421, \mathrm{p}<0.01) .10 \mathrm{MWT}$ 기능적 변 화량 2 와 FRT 기능적 변화량 2 에서는 재활동기와 유의한 상관관계 를 보이지 않았다( $\mathrm{p}>0.05)$.

\section{고 찰}

본 연구는 뇌졸중 환자들을 대상으로 4 주차, 8 주차, 12 주차 기간 동 안 BBS, 10MWT 및 FRT와 같은 기능적 수행능력을 측정하였고, 재활 기간 동안 이러한 기능적 수행능력의 변화가 뇌졸중 환자의 재활동 기와 상관관계를 가지고 있는지 확인하고자 하였다. 우리의 연구결 과에서는 4 주차와 8 주차의 $\mathrm{BBS}$ 의 기능적 변화량 1 에서는 재활동기 와 높은 상관관계를 가지고 있었고, 10MWT와 FRT에서는 중간 정도 의 상관관계를 가지고 있었다. 하지만, 8 주차와 12 주차에서의 기능적 변화량 2에서는 BBS를 제외하고 10MWT와 FRT에서는 유의한 상관 관계를 가지고 있지 않았다. 우리의 연구결과는 뇌졸중 환자들의 재 활동기가 기능적 향상에 영향을 미치는 요인으로 작용할 수 있음을 시사한다.

재활동기란 자신의 능력을 발휘하여 변화된 상황에 적응하기 위 해 재활운동에 참여하고자 하는 심리상태를 의미하며, ${ }^{11}$ 자신의 신체 능력에 대해 지각하고 남아있는 능력을 최대한 활성화시켜 변화된 삶의 형태에 적절하게 적응하기 위해 재활 활동에 참여하려는 심리 적 욕구이다. Park \& $\mathrm{Ko}^{8}$ 의 연구에서 뇌졸중 환자들의 재활동기가 재 활이행(Rehabilitation adherence)에 영향을 미치는지 확인하였고, 이 연구의 결과에서 재활동기와 재활이행 사이에서 낮은 상관관계 $(r=0.30, p=0.01)$ 를 가지고 있음을 확인하였다. 이 연구의 결과는 재 활동기가 재활이행 정도에 영향을 미칠 수 있는 요인으로 작용할 수 있으며, 재활동기가 높을수록 재활을 위한 다양한 중재 활동에 적극 적으로 참여하려는 의지가 높아 수행 능력의 향상 정도도 높아질 수 있음을 시사한다. 우리의 연구결과에서도 4 주와 8 주 사이에 기능적 수행 능력이 재활동기가 높을수록 더 많은 향상이 나타나 높은 혹은 중간 정도의 상관관계를 가지고 있었으며, 이러한 향상은 재활동기 가 높을수록 다양한 치료적 중재에 적극적으로 참여하고 수행함으 로써 나타난 결과라 사료되어진다. 하지만, 선행연구에서는 재활동기 와 재활이행 사이에서 낮은 상관관계를 보이고 있었지만, 우리의 연 구에서는 재활동기와 기능적 향상 정도가 중간 혹은 높은 상관관계 가 나타난 차이를 보이고 있었다. 이와 같은 차이는 선행연구에서 제 시한 재활이행 정도를 평가한 측정항목들이 신체적 능력을 평가한
재활운동(3문항)항목 이외에도 투약이행(5문항), 체위유지(5문항), 재 발예방(4문항), 변비예방(5문항), 욕창예방(3문항), 흡인예방(2문항), 건강행위(2문항)와같은 다양한 요인들을 모두 포함하여 상관관계를 확인하였고, 본 연구에서는 뇌졸중 환자의 기능적 수행능력에 초점 을 맞추었기 때문에 차이가 나타난 것으로 생각되어진다.

$\mathrm{Kim}^{7}$ 의 연구에서도 뇌졸중 환자의 자아존중감 및 재활동기가 높 을수록 일상생활 수행능력이 향상된다고 하였으며, 일상생활 수행능 력의 향상이 이루어지기 위해서는 뇌졸중 환자의 기능수행 능력 향 상과 밀접한 연관성을 갖고 있다고 할 수 있다. Vanessa와 Luis'의 연 구에서도 육체적 활동성은 기능적 능력과 육체적 활동성과 밀접한 관계를 가지고 있다고 보고하였으며, 이 선행연구 결과는 본 연구 결 과를 뒷받침하는 근거라 할 수 있을 것이다. 추가적으로 $\mathrm{Gu} \& \mathrm{Kim}^{17}$ 의 연구에서도 재활동기가 클수록 재활의 시간이 단축되고 재활동 기가 낮을수록 재활속도는 감소된다는 점에서 재활동기와 기능적 향상에서 밀접한 관계가 있음을 확인할수 있었다.

추가적으로 본 연구의 결과에서는 8 주와 12 주 사이에서 기능적 수 행능력의 향상은 재활동기와 낮은 상관관계를 가지거나 유의한 상관 관계가 없는 것으로 나타났다. 이러한 우리 연구의 결과는 재활기간 이 길어지면서 뇌졸중 환자의 재활동기 감소와 관계 있을 것이라 생각 되어진다. $\mathrm{An}^{18}$ 의 연구에서도 뇌졸중 환자의 재활기간이 장기화되면 재활동기는 감소할 수 있다고 보고하였으며, 다른 연구들에서도 발병 기간이 짧을수록 재활동기 점수가 높은 것으로 나타났다. 더욱이, 뇌 졸중 발병 후 6 개월 단위로 구분하여 재활동기의 변화를 살펴 본 연 구에서 발병 후 시간이 길어짐에 따라 점차 재활동기가 증가하다가 2 년이 넘은 시점에서 큰 폭으로 재활동기가 저하된다고 보고하였다. 우 리의 연구에서 뇌졸중 발병 후 13 개월에서 18 개월 대상자 12 명 $(36.3 \%)$ 과 19개월에서 24개월 대상자 13명(39.3\%)으로 구성되어 있었으며, 치 료적 중재가 3 개월이라는 부분을 고려했을 경우에 실험 참여 기간 동 안 재활동기가 감소했을 것이라고 추정할 수 있다. 이와 같이 우리의 연구 결과는 연구 대상자들이 뇌졸중 발병 후 시간의 흐름에 따른 재 활동기의 감소와 한 재활병원에서 장기간 치료를 받으면서 재활동기 가 감소하여 나타난 영향이 기인한 것으로 사료되어진다.

본 연구는 발병 6 개월에서 2 년 이내의 환자들을 대상으로 4 주, 8 주, 12 주 동안 BBS, $10 \mathrm{MWT}$ 및 FRT와 같은 기능적 수행능력을 확인하여 재활동기와 각 기간별 수행능력 변화량의 상관관계를 확인하였으며, 뇌졸중 환자의 재활동기가 높을수록 기능적 능력을 향상 시킬 수 있 는 요인으로 작용할 수 있음을 확인한 연구라 할 수 있다. 그래서 우 리의 연구는 뇌졸중 대상자들의 재활치료 시 대상자의 신체적 기능 능력의 회복에 초점을 둔 행동학적 영역에 대한 중재 이외에도 재활 치료에 동참하려는 재활동기에 대한 심리적 부분도 함께 고려하여 재활프로그램을 설정할 필요가 있음을 시사한다. 하지만 본 연구의 
제한점으로는 첫째, 본 연구는 인지적 문제가 없는 환자들을 대상자 로 하여 인지적 문제가 있는 뇌졸중 대상자들에게는 일반화시킬 수 없다는 것이다. 둘째, 본 연구에서는 3 가지 기능적 수행능력만을 평가 하여 보행과 균형의 질적 변화 등의 변화는 평가하지 못하였다. 셋째, 대상자들의 발병기간이 2 년 이내의 환자들로 실시하여 발병기간이 2 년 넘은 만성 뇌졸중 환자들에게는 일반화시킬 수 없다. 향후 연구에 서는 이러한 문제를 보완한 연구들이 지속적으로 이루어져야 할 것 이다.

\section{REFERENCES}

1. Korean Statistical Information Service, Statistics Korea Daejeon: Korean Statistical Information Service, 2016, KOSIS.

2. Im JH, Lee KS, Kim KY, et al. Follow-up study on mortality in Korean stroke patients. J Korean Med Assoc, 2011;54(11):1199-208.

3. Hong MS, Yom YH, Kim GM, et al. The analysis of trends and contents of nursing intervention research for stroke patients in Korea. AON, 2012;12(4):247-56.

4. Yeo HN. Effects of a group rehabilitation exercise program for stroke patients on their depression and motivation for Rehabilitation. J Korean Clin Nurs Res, 2012;18(3):424-34.

5. Maclean N, Pound P, Wolfe C, et al. Qualitative analysis of stroke patients' motivation for rehabilitation. BMJ, 2000;321(7268):1051-4.

6. Park YS. Implementation of conifer somatic embryogenesis in clonal forestry: technical requirements and deployment considerations. Ann For Sci, 2002;59:651-6.

7. Kim DH, Oh MH, Jung HA, et al. The relationships among ADL, selfEsteem, and motivation for rehabilitation of stroke patients. JKSOT,
2013; 21(4):59-69.

8. Park AS, Ko E. Influences of rehabilitation motivation, self-efficacy and family support on rehabilitation adherence in stroke patients. J Korean Biol Nurs Sci, 2017;19(2):113-22.

9. Lee DY, Lee MS, Na BJ, et al. Related factors of the motivation for rehabilitation in stroke patients. PTK, 2006;13(1):16-23.

10. Kim HS, The impacts of stroke patients' depression, motivation for rehabilitation and activities of daily living on quality of life. KAOT, 2009;17(3):41-53.

11. Kim SY, Kin IN. Factors Convergent Influencing Rehabilitation Motivation among Stroke Patients. J Digit Converg, 2017;15(9):375-84.

12. Han HS, Lim NY. On the Test of the Reliability and validity of the disabled's motivation scale for rehabilitation. Korean J Rehabil Nurs, 2002;5(2):124-33.

13. Dobkin B,.Apple D, Barbeau H, et al. Weight-supported treadmill vs overground training for walking after acute incomplete SCI. Neurology, 2006;66:484-93.

14. Muir S, Berg K, Chesworth B, et al. Use of the berg balance scale for predicting multiple falls in community-dwelling elderly people: a prospective study. APTA, 2008;88(4):449-59.

15. Lee SW, Lee HS. The effect of treadmill-based leg weight loading training on balance and gait in stroke patients. Speci Edu Rehabil Sci Res, 2011;50(1):89-111.

16. Vanessa RS, Luis AG. Physical activity is associated with functional capacity of older women with osteosarcopenic obesity: 24-month prospective study. Eur J Clin Nutr, 2019.

17. Gu BK, Kim HS. A study on the change and level of motivation for rehabilitation. Rehabilitation Research, 1983;9:49-54

18. An ES, Suh SR, Kim EH. Influences of self-esteem, rehabilitation motivation on quality of life in stroke patients with rehabilitation therapy. JKAIS, 2019;20(3):176-87. 